\title{
VALOR DE LA DOCUMENTACIÓN REAL PORTUGUESA PARA LA HISTORIA DE GALICIA EN LA EDAD MEDIA*
}

\author{
PAZ ROMERO PORTILLA ${ }^{1}$
}

\begin{abstract}
Resumen
La especial relación entre Portugal y Galicia durante la Edad Media está ampliamente reflejada en la historiografía. Un mejor conocimiento de los cuantiosos documentos emanados de la cancillería real portuguesa referentes al territorio gallego nos ilustrarán aún más sobre las relaciones mantenidas entre estos territorios, con un pasado común hasta el siglo XII, una cercanía geográfica y lingüística, una pertenencia a una misma jurisdicción eclesiástica y unas relaciones comerciales y de convivencia entre sus habitantes. Ahora bien, estrecha vinculación que originó en ocasiones enfrentamientos y rivalidades.
\end{abstract}

\section{Palabras Clave}

Relaciones Portugal y Galicia. Documentación medieval portuguesa. Historia de Galicia.

\begin{abstract}
The special relationship between Portugal and Galicia during the Middle Ages is widely reflected in historiography. A considerable number of documents coming from the royal Portuguese «cancillería» and concerning Galicia provides us even more information about the relationships maintained by these two territories which shared a common past until the 12th century as well as a geographical and linguistic proximity and belonged to the same ecclesiastical jurisdiction. Both territories also maintained trade relations and had some populations in common. These close ties, however, sometimes led to clashes and rivalries.
\end{abstract}

\section{Key Words}

Relations Portugal and Galicia. Medieval Portuguese documentation. History of Galicia.

\footnotetext{
* Cinco de marzo de 2004.

${ }^{1}$ Profesora de la Universidad de A Coruña.
} 
$\mathrm{E}$ s conocida la estrecha vinculación de Galicia con el reino de Portugal anterior a su independencia y a lo largo de la Edad Media. Muchos son los elementos que hicieron que existiera una mayor conexión: cercanía geográfica, pasado común hasta el siglo XII, misma lengua, pertenencia a una misma jurisdicción eclesiástica, relaciones comerciales, convivencia entre sus habitantes y, ¿por qué no decirlo también?, momentos de enfrentamiento y rivalidad. Esta especial relación se vio favorecida por la difícil situación por la que atravesaron las monarquías peninsulares, la formación del reino de Portugal y sus problemas con León y Castilla o la inestabilidad política del reino castellano. Una buena muestra de esta singular vinculación son los cuantiosos documentos que existen en archivos portugueses y españoles referente a las relaciones entre Galicia y Portugal durante este tiempo ${ }^{2}$, y dentro de estos queremos destacar especialmente los de la cancillería real portuguesa referentes a Galicia, donde encontramos donaciones a catedrales y monasterios, cuestiones y problemas eclesiásticos, asuntos comerciales, usurpaciones de tierras, invasiones, etc.

Los diferentes acontecimientos históricos han dejado un reflejo documental, por lo que una buena manera de conocer mejor la historia de Galicia será trabajar con la documentación portuguesa al respecto. Su pasado común hasta la independencia del reino de Portugal generó profundas raíces y vínculos difíciles de olvidar, por lo que no es de extrañar que las conexiones y especial convivencia pervivieran a lo largo de tantos siglos. La visión y actitud de los reyes portugueses hacia el territorio gallego fue distinta que hacia el resto del reino de León o de Castilla. La cercanía política, geográfica, eclesiástica y social reflejada en la documentación real portuguesa nos habla de esta singular relación entre Portugal y Galicia.

Desde que Alfonso VI entregó en 1095 los territorios entre el Miño y el Tajo, la parte más expuesta del antiguo reino de Galicia, a Enrique de Borgoña para hacer frente a la ofensiva almorávide, comenzó el camino para la independencia de Portugal. El conde Enrique colaboró con la nobleza local, que le facilitó la administración interna del territorio a la vez que conseguía el apoyo de los obispos y principales instituciones eclesiásticas. Conocemos además donaciones hechas por el conde Enrique a la iglesia de Santiago y a la catedral de Tuy ${ }^{3}$. El conde Enrique promovió

\footnotetext{
${ }^{2}$ Ver ROMERO PORTILLA, Paz, «La singular relación Portugal-Galicia y su reflejo en la documentación medieval», en Revista de Ciências Históricas, Porto, XV (2000), pp. 53-69.

${ }^{3}$ 1097.12.09. El conde Enrique de Portugal y su mujer Teresa dan licencia a los vecinos de Correlhâ, que pertenecen a la iglesia de Santiago, para que puedan llevar sus ganados y cortar leña en los bosques del fisco real. Archivo Catedral de Santiago, Tumbo A, f. 39v. LUCAS ÁLVAREZ,
} 
el repoblamiento de regiones menos habitadas y apoyándose en los poderes locales comenzó su lucha contra los musulmanes. En el siglo XII emergen corrientes regionales que intentan aprovechar la difícil situación para conquistar posiciones y fortalecerse buscando más libertad de movimiento para intervenir en la política, las ciudades procuran la independencia de las autoridades señoriales y los nobles tratan de gobernar grandes territorios. Muerto Enrique de Borgoña su mujer Teresa se vio presionada por fuerzas contrarias: los nobles portugueses que querían una mayor autonomía respecto a Galicia y los magnates gallegos que buscaban la reunificación de Portugal y Galicia. El proyecto de matrimonio de la condesa Teresa con el noble gallego Bermudo Pérez de Trava se presentó como una posible solución al problema, ya que Alfonso el hijo de Urraca y Raimundo de Borgoña sería rey de León y un descendiente de los Trava rey de Galicia. Desde 1117 Teresa comenzó a usar en los documentos el título de reina por el derecho que tenía al ser hija de Alfonso VI. La difícil situación en la frontera sur de Portugal debida a la presión almorávide de los años 1116 y 1117 hizo que Teresa necesitase de la ayuda gallega para hacer frente a la ofensiva.

En 1120 comenzó la disputa entre las diócesis de Braga y de Santiago por las demás diócesis, lucha que no terminará hasta 1199. Cuando en 1119 fue elegido Papa Calixto II, hermano del conde Raimundo de Borgoña y por tanto tío del futuro Alfonso VII, el arzobispo de Santiago Gelmírez aprovechó para obtener privilegios para la iglesia compostelana. En 1120 se le atribuyeron los derechos metropolitanos de Mérida y se menciona a Coimbra y Salamanca como sufragáneas de Santiago de Compostela, consiguiendo además que se suspendiera a Payo Mendes en sus funciones de obispo de Braga, todo lo cual significaba una victoria del arzobispo de Compostela que además reforzó su poder en Galicia con la protección de doña Urraca. Aprovechando el momento, Urraca y Diego Gelmírez invadieron Portugal saqueando el territorio, por lo que la condesa Teresa tuvo que someterse a su hermana, pero pronto consiguió separar a sus adversarios y obtener el señorío de Ourense, y además el arzobispo Gelmírez perdió algunas de las ventajas adquiridas sobre la diócesis de Braga. La conexión de Teresa con tierras orensanas está reflejada en algunos documentos, como la donación hecha a la cate-

Manuel, Tumbo A de la Catedral de Santiago, Santiago de Compostela 1998, $\mathrm{n}^{\circ}$ 97, pp. 208-09; 1110.04.02. Tuy. El conde Enrique dona el monasterio de Ázere a la catedral de Tuy. Archivo Distrital de Braga. Cart. da Mitra, ms. de G. A. de Lousada Machado, f. 5v. AZEVEDO, Rui Pinto de, Documentos medievais portugueses: documentos régios, documentos dos condes Portucalenses e de D. Afonso Henriques (1095-1185), Lisboa, 1958, vol. I, T. I, doc. 12, pp. 503-04. Esta última hay que entenderla debido a su pertenencia a la diócesis de Braga. 
dral de Ourense de bienes y derechos señoriales, garantía de protección a sus habitantes y el hecho de establecer en la ciudad un mercado mensual ${ }^{4}$. Años después donó al monasterio de Montederramo el lugar de Rovoyra Sacrata con privilegio de exención jurisdiccional, y curiosamente en el documento tras la fecha aparece la expresión Regnante regina domna Tarasia in Portugale et Limia usque riuulum spaliosum, donde comprobamos que se titulaba reina de Portugal y de Limia, territorio gallego ${ }^{5}$.

El año 1121 estuvo repleto de importantes acontecimientos para el condado de Portugal: en primer lugar el acercamiento de la condesa Teresa a la familia de los Trava, opositores a Gelmírez en Galicia, lo que motivó que Pedro Froilaz comenzase a desempeñar importantes funciones en Portugal; en segundo lugar el arzobispo de Braga consiguió que el Papa le reconociera los derechos metropolitanos sobre la diócesis de Viseu, Lamego e Idanha, pertenecientes a la provincia de Mérida y que teóricamente debían ser sufragáneas de Compostela, y en tercer lugar comenzó a prepararse una revuelta de nobles portugueses que se intensificó en 1125 y a la que se unirá dos años después el infante Alfonso Enriquez.

No sólo encontramos donaciones de Teresa a la iglesia orensana sino que también sabemos de donaciones a la catedral de Tuy, como ya lo habíamos visto con su marido el conde Enrique. Así, en 1125 le donó el monasterio de Ázere y las iglesias de San Cosme y Damián y varias iglesias situadas entre los ríos Miño y Limia, otorgándole importantes privilegios ${ }^{6}$. Finalmente donó en 1127 al monasterio de Pombeiro el monasterio de Vimieiro, en territorio bracarense ${ }^{7}$. Tras la muerte de Urraca su hijo Alfonso fue coronado rey de León y de Castilla y un año después se reunió en Zamora con su tía Teresa y Fernán Pérez de Trava estableciendo un acuerdo de paz. Pero no había terminado el año cuando Alfonso VII tuvo que enfrentarse con la condesa Teresa, que quería ejercer su autoridad no sólo en

${ }^{4}$ 1112.02.17. Archivo Catedral de Ourense, Privilegios, Tomo I, doc. 4. AZEVEDO, op. cit., vol. I., T. I, doc. 60 , pp. 75-6.

5 1124.08.21. Allariz. Archivo Histórico Nacional. Clero. Montederramo, carp. 1481, $\mathrm{n}^{\mathrm{o}} 3$. AZEVEDO, op. cit., vol. I., T. I, doc. 68, pp. 84-5. SÁNCHEZ BELDA, Luis, Documentos reales de la Edad Media referentes a Galicia, Madrid, 1953, nº 202, pp. 98-9.

6 1125.09.02. Archivo Catedral de Tuy, Libro tercero de privilegios, perg. 1; A. D. de Braga. Col. Cron. Cart. de Mitra, ${ }^{\circ}$ 7. AZEVEDO, op. cit., vol. I., T. I, doc. 70, pp. 87-8; FLÓREZ, Enrique, España Sagrada, Madrid, 1747-1761, XVIII; 1125.09.04. A. D. de Braga. Col. Cron. Cart. de Mitra, $\mathrm{n}^{\circ}$ 8. AZEVEDO, op. cit., vol. I., T. I, doc. 71, pp. 88-9.

${ }^{7}$ 1127.05.23. LUCAS ÁLVAREZ, Manuel - LUCAS DOMÍNGUEZ, Pedro, El priorato benedictino de San Vicenzo de Pombeiro y su colección diplomática en la Edad Media, A Coruña, 1996, doc. 6 , p. 60 . 
Portugal sino también sobre el condado de Toroño, donde hizo donación a la catedral de Tuy de la mitad de la tierra de realengo de Fonte Arcada perteneciente a Arcos de Valdevez ${ }^{8}$ y su hijo donó al monasterio de Montederramo, en Ourense, una propiedad en Ribeira do Solar, en tierra de Viera, con la iglesia de San Juan de Cova en el concejo de Paredes de Coura9.

En 1128 tuvo lugar la batalla de San Mamed donde los nobles portugueses apoyaron al infante Alfonso Enriquez porque no aceptaban la política de la nobleza gallega ni un reino que reunificase Galicia y Portugal. Tras la batalla Alfonso Enriquez tomó el gobierno del condado de Portugal y comenzó a usar el título de rey o infante pero nunca el de conde, reivindicando así sus derechos por ser nieto de Alfonso VI. La muerte de su madre en 1130 legitimó su situación a la vez que significó la exclusión de Fernán Pérez de Trava del panorama político. Alfonso Enriquez procuró extender en varias ocasiones su dominio sobre Toroño y Limia, pero Alfonso VII restableció su soberanía en estos condados gallegos. Estos acontecimientos quedaron reflejados en la documentación, como muestra la donación con plenos poderes hecha a Sancho Rodríguez de las heredades de Casal de Ramondo y Gaindi, situadas en Ourense ${ }^{10}$, y la donación de 1136 al monasterio de Tojosoutos de la villa de Paredes, situada en el concejo de Viana do Castelo ${ }^{11}$. En 1137 tuvo lugar un encuentro entre los dos primos en Tuy y Alfonso VII obtuvo el juramento de fidelidad de Alfonso Enriquez ${ }^{12}$, sometimiento al rey castellano tal vez motivado por la necesidad de ayuda ante la presión sarracena en el sur de Portugal $^{13}$. Entre 1139 y 1140 Alfonso Enriquez comenzó a utilizar el título de rey y para tener mayor independencia respecto de Alfonso VII se hizo vasallo del Papa

\footnotetext{
${ }^{8}$ (1128) AZEVEDO, op. cit., vol. I., T. I, doc. 13, p. 517.

9 1128.07.08. Braga. A.H.N. Clero. Montederramo, m. 1107, particular 3. AZEVEDO, op. cit., vol. I. T., I, doc. 92, pp. 115-16.

${ }^{10} 1130.01 .18$. Villaza. A.H.N. Tumbo de Celanova, f. 96r. SERRANO Y SANZ, M., «Documentos del monasterio de Celanova», en Revista de Ciencias Jurídicas y Sociales, XXII (1929) pp. 44-5; AZEVEDO, op. cit., vol. I., T. I, doc. 113, p. 136. SÁNCHEZ, op. cit., nº 207, p. 101.

${ }^{11}$ 1136.05.19. A.H.N. Clero. Tojosoutos, carp. 556, $\mathrm{n}^{\circ}$ 2; Códice Tumbo de Tojosoutos, f. 34. AZEVEDO, op. cit., vol. I., T. I, doc. 154, pp. 183-84; SÁNCHEZ, op. cit., n² 219, pp. 106-07.

${ }^{12}$ 1137.07.04. Tuy. «Tratado de paz entre el emperador y el infante de Portugal». ESCALONA, R., Historia del Real Monasterio de Sahagún, Madrid, 1782, apéndice III, 527-528, escr. CLXI; FERNÁNDEZ FLÓREZ, Jose Antonio, Colección diplomática del Monasterio de Sahagún (8571300), León, 1991, doc. 1263, p. 161; AZEVEDO, op. cit., vol. I., T. I, doc. 160, p. 194.

${ }^{13}$ En 1137 Alfonso Enriquez donó a la iglesia de Tuy la villa de Vinea. A. C. Tuy. Libro 5 de privilegios reales, doc. 3. GALINDO ROMEO, Pascual, Tuy en la Baja Edad Media. Siglos XII-XV, Madrid, 1923, doc. III, pp. VIII-IX.
} 
en $1143^{14}$. Prácticamente 43 años después de que Alfonso VI separara Portugal de Galicia y lo entregara al conde Enrique por su casamiento con su hija Teresa, el antiguo condado de Portugal se declara independiente del reino castellano-leonés. Alfonso Enriquez trasladó su corte a Coimbra buscando distanciarse de la nobleza señorial del norte, a la que debía su poder pero de la que no quería depender. Desde 1143 abandonó durante varios años sus pretensiones sobre los territorios gallegos para consagrarse a la conquista de tierras en su frontera meridional. Eclesiásticamente restauró las tres antiguas diócesis pertenecientes a Mérida y por tanto sufragáneas de Santiago. En 1147 nombró obispos de Lisboa, Viseu y Lamego que fueron consagrados por el arzobispo de Braga, que afirmó su independencia de las iglesias de Santiago y Toledo, por lo que recibió una protesta de Alfonso VII y una respuesta del Papa Eugenio III en 1148.

Hemos visto cómo la situación de dependencia de algunas iglesias gallegas de la diócesis de Braga motivó abundante documentación real portuguesa al respecto, y en este momento no es extraño encontrarnos algún documento al respecto como el de Alfonso I de Portugal informando al arzobispo de Braga de la elección de Juan, abad del monasterio de Samos, como obispo de Lugo ${ }^{15}$. No podemos olvidar que las diócesis gallegas, exceptuando Santiago de Compostela, pertenecieron al arzobispado de Braga al que prestaban obediencia ${ }^{16}$ durante la mayor parte de la

\footnotetext{
${ }^{14}$ Referencia al documento de Inocencio III (1203.06.26. Ferentini), según el cual Alfonso I de Portugal se reconoció feudatario de la Santa Sede en tiempos de Lucio II. Archivo Secreto Vaticano. Archivio di Castel S. Angelo. Arm. I-XVIII, $\mathrm{n}^{\circ}$ 4212. MANSILLA, Demetrio, La documentación española del Archivo del «Castel S. Angelo» (395-1498), Roma 1959, doc. 57, p. 37. El documento de Inocencio III en MANSILLA, Demetrio, La documentación pontificia hasta Inocencio III (9651216), Roma, 1955, n² 282, p. 317.

${ }^{15}$ (1152) A. D. Braga. Liber Fidei, f. 99v, doc. 343; f. 106, doc. 370; f. 151v-152, doc. 578. FLÓREZ, op. cit., XLI, 311; COSTA, Avelino Jesús, Liber Fidei sanctae bracarensis ecclesiae. Braga, 1965, T. II, doc. 579, p. 4; SANTOS ACEVEDO, Mª José, Contributo do Liber Fidei para o estudo de alguns aspectos das relações eclesiásticas entre Braga e Galiza nos séculos XI-XIII, Coimbra, 1986, doc. 343, p. 19.

${ }^{16}$ (1152) El obispo de Lugo Juan presta obediencia como su metropolitano al arzobispo de Braga. A. D. Braga. Liber Fidei, f. 139, doc. 515. COSTA, op. cit., doc. 515, p. 313; SANTOS, op. cit., doc. 515, p. 19; (1158) Isidoro, obispo de Tuy, presta obediencia al arzobispo de Braga. A. D. Braga. Liber Fidei, f. 70. COSTA, op. cit., doc. 213, p. 19; (1159-1161) Juan, obispo de Lugo, agradece al arzobispo de Braga el recibimiento hecho al maestro Suero y las instrucciones relativas al abad de Samos. A. D. Braga. Liber Fidei, f. 99r-v. COSTA, op. cit., doc. 342, pp. 26-7; LUCAS ÁLVAREZ, Manuel, El Tumbo de Julián de Samos (siglos VIII-XII), Santiago, 1986, doc. S-25, pp. 478-79; (1168) Juan obispo de Tuy presta obediencia al arzobispo de Braga. A. D. Braga. Liber Fidei, ff. 70v-71. COSTA, op. cit., doc. 214, p. 248; 1169. Juan, obispo de Mondoñedo, presta obediencia como su metropolitano al arzobispo de Braga. A. D. Braga. Liber Fidei, f. 146v, f. 149.
} 
Edad Media, hasta que a finales del siglo XIV se integraron en la provincia eclesiástica compostelana.

Tras la muerte de Alfonso VII y la división del reino entre sus hijos Fernando II de León y Sancho III de Castilla, Alfonso Enriquez aprovechó para comenzar una nueva ofensiva contra Toroño y en 1159 llegó a tomar Tuy, capital del condado. Reflejo de esta presencia del rey portugués en Tuy es el acuerdo que se firmó allí sobre el matrimonio de su hija Mafalda con el conde de Barcelona y príncipe de Aragón, Raimundo ${ }^{17}$. Un año después tuvo lugar en el monasterio de Celanova un acuerdo por el que Alfonso Enriquez restituyó a Fernando II la ciudad de Tuy y su territorio, pero la paz duró poco ya que en 1162 encontramos a Alfonso Enriquez ejerciendo actos de soberanía sobre el condado de Limia, y un año después consiguió hacerse nuevamente con el condado de Toroño. Hasta 1165 ejerció su dominio sobre los dos condados gallegos, por lo que tuvo lugar un nuevo tratado de paz con Fernando II celebrado en Pontevedra. En el acuerdo se decidió el matrimonio de Urraca Alfonso con el rey de León, que se celebró en 1166, y Alfonso Enriquez abandonó Tuy por lo menos hasta $1168^{18}$.

La organización eclesiástica en esta zona fue bastante complicada ya que la iglesia de Santiago tenía jurisdicción sobre varias diócesis de Portugal, y la de Braga ejercía derechos metropolitanos en otras diócesis del reino de León. En ocasiones obispos leoneses fueron nombrados para juzgar cuestiones en territorio portugués y obispos portugueses en territorio leonés, como vemos reflejado en diversos documentos. Así, en 1211 el Papa Inocencio III confirmó el testamento del rey Sancho I de Portugal y encargó que las infantas Teresa y Sancha fueran defendidas por el arzobispo de Santiago y el obispo de Zamora ${ }^{19}$, y en 1217 los

COSTA, op. cit., doc. 550, p. 347; (1174) Bertrán, obispo de Tuy, presta obediencia al arzobispo de Braga. A. D. Braga. Liber Fidei, f. 138v. COSTA, op. cit., doc. 512, p. 311; (1176) Rabinaldo, obispo de Mondoñedo, presta obediencia como su metropolitano al arzobispo de Braga. A. D. Braga. Liber Fidei, f. 138v. COSTA, op. cit., doc. 510, p. 310.

${ }^{17}$ 1160.01.30. Tuy. Códice Antg. de Braga. Monarchia Lusitana, p. 3, liv. 10, cap. 41, f. 195. História Genealógica das Casas Reales, Tomo 6 das Prov. Liv. 14, nº 8, p. 195. BARBOSA, Jose, Catálogo cronológico, histórico, genealógico e crítico das rainhas de Portugal e seus filhos. Lisboa, 1727, f. 119.

${ }^{18}$ Existe una donación de Alfonso Enriquez a la catedral de Tuy del 28 de marzo de 1169, pero este acto no implica el ejercicio de soberanía. A. Catedral de Tuy, Libro 4 de privilegios reales, doc. 7. GALINDO, op. cit., doc. VI, p. XI; AZEVEDO, op. cit., vol. I. doc. 293, pp. 381-83.

${ }^{19} 1211.10 .07$. Letrán. A. S. V. A. A. Arm. I-XVIII, no 4212. MANSILLA, La documentación española, doc. 59, p. 38; MANSILLA, Demetrio, La documentación Pontificia de Honorio III (12161227), Roma, 1965, $\mathrm{n}^{\circ} 4458$, p. 487. (1212-1227) Breve referencia al pleito entablado entre Alfonso II de Portugal y sus hermanas Sancha y Teresa con motivo de la ejecución del testamento de su 
obispos de Lugo y de Burgos y el deán de Compostela ayudan al rey Alfonso II de Portugal y a sus hermanas Sancha y Teresa para acabar con la contienda que mantenían ${ }^{20}$.

Nuevos intentos del rey portugués, ahora Sancho I, contra la frontera gallega tuvieron lugar en 1197 ocupando Tuy y Pontevedra ${ }^{21}$. Con todo, el dominio duró poco ya que un año después los territorios gallegos volvieron al rey de León. Pocos años antes Sancho I, siguiendo la tradición de sus padres, hizo donaciones a la iglesia de Tuy $^{22}$ y al monasterio de San Justo de Tojosoutos le confirmó la donación de la villa de Paredes junto al río Limia ${ }^{23}$. A comienzos del siglo XIII tuvo lugar un fuerte enfrentamiento de Sancho I con los obispos portugueses, primero con el obispo de Braga lo que motivó la intervención del Papa Inocencio III en 1210, y después con el obispo de Coimbra al que llegó a apresar, hasta que en 1211 el Papa nombró al arzobispo de Santiago juez apostólico encargado de restituir al prelado en sus bienes. Los problemas con la Iglesia continuaron durante el reinado de Alfonso II que llegó a ser excomulgado por el arzobispo de Braga. Los monarcas portugueses habían perdido el apoyo eclesiástico. El rey protestó ante la curia romana y en 1212 el Papa buscó una solución al problema para que se respetasen los derechos regios. En 1213 se ordenó a los jueces eclesiásticos que absolvieran al rey de la excomunión. Con todo, el enfrentamiento con el arzobispo de Braga continuó y Sancho I fue nuevamente excomulgado, por lo que el rey reaccionó efectuando represalias sobre los bienes del arzobispo, algunos de ellos en tierras gallegas, por ejemplo en el coto de Ervededo en Limia, pero los portugueses tuvieron que retirarse. El arzobispo de Braga apeló al Papa Honorio III que en 1220 encargó a los obispos de Palencia, Astorga y Tuy que confirmaran la sentencia de

padre Sancho I, por cuya causa Pedro, arzobispo de Santiago, y Martín, obispo de Zamora, lanzaron sentencia de excomunión. Más tarde intervinieron los obispos de Plasencia y Ourense y los abades de Osera y Espina en tiempos del Papa Honorio III. A. S. V. A. A. Arm. I-XVIII, $n^{\circ} 4212$. MANSILLA, La documentación española, doc. 60, p. 38; MANSILLA, La documentación pontificia, ${ }^{\circ} 486$, pp. 504-49.

${ }^{20} 1217.08 .08$. Fiorentina. Reg. Vat. 9, f. 141v, $\mathrm{n}^{\circ} 553$. MANSILLA, La documentación de Honorio III, doc. 77, pp. 63-4. Monumenta Hispaniae Vaticana, sección registros, vol. II.

${ }^{21}$ 1198. Las tropas portuguesas en la campaña contra el rey de León Alfonso IX tomaron Pontevedra, Sampayo de Lombeo, Tuy y otros lugares. LEÂO, Duarte Nunes, Crónicas dos reis de Portugal, Ed. 1975, Chronica del rei dom Sancho o I, p. 105.

${ }^{22}$ 1186.07. Coimbra. Sancho I de Portugal hizo donaciones a la iglesia de Tuy en Mahazedo. A. C. de Tuy, Libro 4, doc. 23. GALINDO, op. cit., doc. XV, pp. XVIII-XIX.

${ }^{23}$ 1187.01.01. Guimarães. A.H.N. Clero. Tojosoutos, carp. 556, $\mathrm{n}^{\circ} 2$. Códice Tumbo de Tojosoutos, f. 34. SÁNCHEZ, op. cit., doc. 419, p. 195.

Cuadernos de Estudios Gallegos, Tomo LI, Fascículo 117, Santiago 2004. (Págs. 219 - 237) 
excomunión del rey portugués ${ }^{24}$. Son abundantes los documentos referentes a la intervención de obispos de diócesis del reino leonés que en el conflicto de Alfonso II con la iglesia portuguesa ${ }^{25}$.

A pesar de todos estos problemas internos del rey lusitano conocemos algunos textos de donación en relación con Galicia ${ }^{26}$. Continuando con la tradición de los reyes portugueses de donaciones a monasterios gallegos, en 1224 Sancho II confirmó al de San Justo de Tojosoutos la entrega de la villa de Paredes junto al río Limia $^{27}$. Años después eximió al de Santa María de Oya y sus dependencias del

${ }^{24}$ 1220.12.22. Letrán. Honorio III manda al rey Alfonso II de Portugal dar la debida satisfacción al arzobispo de Braga, Esteban Soares de Silva, por las injurias y daños que le ha ocasionado. En caso contrario mandará a los obispos Tello de Palencia, Pedro de Astorga y Esteban de Tuy publicar solemnemente la sentencia de excomunión en todo su reino. A. S. V. A. A. Arm. I-XVIII, n 4216. MANSILLA, La documentación pontificia de Honorio III, doc. 62, p. 39.

${ }^{25} 1220.12 .13$. Letrán. El Papa envía al obispo de Astorga y al obispo y deán de Tuy la bula Sua Nobis en la que les autoriza a amonestar al rey Alfonso II e inducirlo a entregar al arzobispo de Braga la jurisdicción de la ciudad de Peñafiel, Amares y otras tierras. A. S. V. A. A. Arm. XXXII, n ${ }^{\circ}$ 5, f. 100. MANSILLA, op. cit., doc. 348, p. 259; 1220.12.23. Letrán. Los obispos de Astorga y Tuy deben obligar al rey de Portugal a entregar al arzobispo de Braga las posesiones que le quitó. A. S. V. A. A. Arm. XXXII, n 5, f. 101. MANSILLA, op. cit., doc. 349, p. 260; 1221.01.04. Letrán. Los obispos de Palencia, de Astorga y de Tuy quieren que Alfonso II de Portugal deje de perseguir al arzobispo de Braga. MANSILLA, op. cit., doc. 357, pp. 263-64. Monumenta Hispaniae, vol. II; 1221.03.16. Letrán. El obispo, deán y arcediano de Tuy deben procurar que Alfonso II no moleste al obispo e iglesia de Oporto. Ms. Bib. Vallic., 53, f. 108. MANSILLA, op. cit., doc. 370, p. 275; 1221.12.13. Letrán. El arzobispo de Compostela, el obispo de Ourense y el abad de Osera obligan al rey Alfonso II a cumplir la última voluntad de su mujer. MANSILLA, op. cit., doc. 383, p. 285; 1222.06.16. Alatri. Bula Etsi Venerabili del Papa Honorio III al rey Alfonso II mostrándole su desagrado por sus acciones e indicándole que atienda las exhortaciones y los avisos que por su orden le hacen los obispos de Palencia, Astorga y Tuy. A. D. Braga. Bulario. PINTO, Leite, Discurso da Sessão de Encerramento do Congresso, en Bracara Augusta, Braga (1950) vol. XVIIIXIX, $\mathrm{n}^{\circ} 18-19$, doc. 80; (1222).06.16. Alatri. El Papa Honorio envía al abad de la orden del Cister y al abad y prior de Celanova la bula Noveritis Vos incluyendo la que dirigió al rey de Portugal Alfonso II. VASCONCELOS, María da Assunção Jacome - ARAUUJO, António de Sousa, Bulário Bracarense: sumários de diplomas pontificios dos séculos XI a XIX. Braga 1986, doc. 74, pp. $53-$ $4 ; 1222.06 .06$. Alatri. Los abades de Osera y de Celanova deben advertir al rey de Portugal que no persiga más a la iglesia de Braga. Reg. Vat. 11, f. 252, nº 439. MANSILLA, op. cit., doc. 407, pp. 301-02; 1223.12.23. Letrán. Los obispos de Astorga, Ourense y Tuy deben advertir al rey de Portugal que deje de perseguir a la iglesia de Braga. Reg. Vat. 11, f. 60, $\mathrm{n}^{\circ} 297$. MANSILLA, op. cit., doc. 346, pp. 257-58.

${ }^{26}$ (1211-1223) Alfonso II de Portugal y su mujer Urraca donan al abad del monasterio de Pelayas la ermita de San Pedro de Teta. SÁNCHEZ, op. cit., doc. 530, p. 238.

${ }^{27}$ 1224.11.16. Guimarães. A.H.N. Clero. Tojosoutos, carp. 556, $\mathrm{n}^{\circ} 2$; Códice Tumbo de Tojosoutos, f. 34. SÁNCHEZ, op. cit., n ${ }^{\circ}$ 532, p. 238. 
portazgo de las mercancías que salieran o entraran de su reino ${ }^{28}$. Durante el reinado del nuevo monarca los problemas con la iglesia continuaron ${ }^{29}$ y complicadas querellas opusieron a Sancho II con algunos obispos del reino. El obispo de Lisboa fue a Roma en 1231 para defender su causa y obtuvo del Papa Gregorio IX violentos documentos pontificios contra el rey que fue puesto en entredicho en el reino. Tras la muerte del obispo al año siguiente, la sucesión fue disputada por varios candidatos y la intervención de la corte real agravó el conflicto existente, hasta que finalmente en 1244 se nombró al obispo gallego Aires Vásquez. En Oporto los problemas comenzaron en 1227 cuando una bula acusó a Sancho II de intervenir abusivamente. En 1233 el obispo Margino Rodrigues que se encontraba en Roma obtuvo varias textos pontificios que acusaban al rey, entre otras cosas, de no respetar la jurisdicción temporal del obispo sobre la ciudad. Dos años después el nuevo obispo de Oporto Pedro Salvadores obtuvo del Papa Gregorio IX la facultad de absolver de la excomunión a los oficiales regios que dañaban su diócesis. Este mismo Papa envió la bula Si Quam Graviter al obispo de Ourense concediéndole poder para poner en entredicho al rey de Portugal si no respetaba los derechos otorgados por su padre a la iglesia de Braga ${ }^{30}$. El conflicto terminó en $1238^{31}$.

Sin embargo, los problemas de los reyes portugueses con la iglesia local continuaron durante el reinado de Alfonso III, hermano de Sancho II. El monarca mantuvo un enfrentamiento con el conjunto de los obispos del reino, incluidos aquellos que debían su nombramiento al rey, excepto el de Lisboa ${ }^{32}$. En 1268 estos

${ }^{28}$ 1245.08.15. Guimarães. A.H.N. Clero. Oya, leg. 1.247. SÁNCHEZ, op. cit, nº 712, p. 307.

${ }^{29}$ La documentación refleja este problema de Sancho II con la iglesia portuguesa. Sirvan de ejemplo algunos textos: 1224.01.16. Letrán. El obispo de Ourense debe advertir a Sancho II que abandone la persecución de la Iglesia. Reg. Vat. 12, f. 140, n 191. MANSILLA, op. cit., doc. 489, pp. 356-59. Monumenta Hispaniae, vol. II; (1217-1227) Honorio III manda a los obispos de Astorga y Tuy recabar información sobre los agravios cometidos por Sancho II y tomar medidas para acabar con ellos. A. S. V. A. A. Arm. I-XVIII, no 4237. MANSILLA, op. cit., doc. 61, pp. 38-9.

${ }^{30}$ (1238) 04.20. Letrán. VASCONCELOS, op. cit., doc. 96 y 97, p. 59.

${ }^{31}$ El enfrentamiento de Sancho II con la Iglesia continuó, como podemos comprobar en un documento del Papa Inocencio IV fechado en Lión el 24 de julio de 1245, donde manda a los grandes y nobles de Portugal que, depuesto el rey Sancho II por su imbecilidad y mal proceder, reconozcan a su hermano Alfonso, conde de Bolonia, por verdadero gobernador de Portugal. A. S. V. A. A. Arm. I-XVIII, n 4212. MANSILLA, op. cit., doc. 85, pp. 48-9.

${ }^{32}$ En una documento de fecha (1255.05.13. Nápoles) Alejandro IV excomulgó al rey portugués por haber abandonado a su verdadera esposa Matilde, hija del conde de Bolonia, y haberse unido con Beatriz de Guzmán, hija natural de Alfonso X de Castilla. Esta unión fue legitimada después de morir su primera esposa. A. S. V. A. A. Arm. I-XVIII, no 4212. MANSILLA, op. cit., doc. 86, p. 49. SANTAREM, Visconde de, Quadro elementar das Relações Políticas e Diplomáticas de Portugal com as Diversas Potências do Mundo, Paris, 1842-1866, 9, pp. 176-79. 
presentaron al Papa una extensa lista de acusaciones contra el rey por el desprecio a las sanciones eclesiásticas por parte de los jueces y merinos regios, la resistencia de las autoridades regias a la implantación del diezmo para el clero, la oposición a una extensión de los privilegios eclesiásticos previstos en el derecho canónico, la oposición regia a la extensión de la propiedad y de la jurisdicción eclesiástica en detrimento de las tierras y de los derechos de la Corona, etc. Todas estas cuestiones habían además suscitado numerosas querellas locales y las pequeñas batallas y escaramuzas dispersas habían dado lugar a una guerra generalizada que oponía al clero, no sólo con el rey y sus representantes, sino también con los concejos. Los obispos portugueses pusieron en entredicho al rey en todas las diócesis del reino salvo en Lisboa. Contamos con un documento precisamente de ese año 1268 en que se habla de las ofensas cometidas por Alfonso III contra los obispos de Portugal y de Tuy ${ }^{33}$. El monarca acudió al Papa y Clemente IV le levantó el entredicho y le recomendó enmendar sus actos de opresión a la iglesia.

Son también frecuentes en la documentación real portuguesa referente a Galicia la intervención de los monarcas por intercambios de propiedades (por ejemplo de Alfonso III de Portugal cambia con el obispo de Tuy diversas propiedades de Camiña y Puente de Limia y en la iglesia de Vinha ${ }^{34}$ ), o por problemas derivados de anteriores donaciones. En este último sentido podemos reseñar la carta de 1268 en que Alfonso III comunica a su merino mayor las quejas recibidas por el abad del monasterio de Pelayas contra los señores que le disputaban la posesión de la ermita de San Pedro de Teta, donada al monasterio por Alfonso II. El rey ordena a su mayordomo mayor que vea la carta de donación y que si es cierta ampare al abad en su posesión ${ }^{35}$.

Durante el reinado de Dionis encontramos diversos documentos referidos a monasterios gallegos como el debido a una queja recibida del abad de Montederramo, en el que ordenó al juez de Bragança que obligase a Mayor

${ }^{33}$ 1268.08.01. Viterbo. Guillermo Folquini canónigo de Narbona recibe instrucciones del Papa Clemente IV contra Alfonso III de Portugal por las ofensas cometidas contra los obispos de Portugal y de Tuy. DOMÍNGUEZ SÁNCHEZ, Santiago, Documentos de Clemente IV (1265-1268) referentes a España, León, 1996, doc. 196, pp. 323-25.

${ }^{34}$ Archivo Nacional Torre do Tombo. Corporações religiosas. Colegiada de Valença. Documentos referentes ao cabido de Tui, $\mathrm{n}^{\circ} 4$. MARQUES, José, Relações entre Portugal e Castela nos finais da Idade Média: o Censual do Cabido de Tui para o arcediago da terra da Vinha 1321, Braga, 1994, doc. 5, pp. 98-100.

${ }^{35}$ 1268.04.18. Santarem. A.H.N. Clero. Montederramo, carp. 1485, $\mathrm{n}^{\circ} 1$. SÁNCHEZ, op. cit., $\mathrm{n}^{\circ}$ 780 , p. 339.

Cuadernos de Estudios Gallegos, Tomo LI, Fascículo 117, Santiago 2004. (Págs. 219 - 237) 
Fernández a devolver el cereal que había cogido y pertenecía a dicho monasterio ${ }^{36}$. Entre esta documentación hay que subrayar la relativa al monasterio de Santa María de Oya donde encontramos una especial protección, tal vez debida a su situación territorial. En el año 1281 el rey portugués tomó bajo su amparo este monasterio y prohibió cualquier acto de violencia contra él ${ }^{37}$. Un año después este mismo monarca ordenó, a petición del abad y del monasterio, que no se exigieran servicios al monasterio, ya que poseía privilegio de exención por sus posesiones en Portugal concedido por sus reyes ${ }^{38}$. En un documento de 1293 Dionis ordenó a Gonzalo Fernández, su merino mayor entre el Duero y el Miño, que no consintiera que se llevaran ante los jueces laicos los pleitos pertenecientes al monasterio ni que los justicias prendiesen sus bienes ${ }^{39}$. En otra carta con la misma fecha que el documento anterior ordenó a los alcaldes de Valença do Miño que respetasen e hiciesen respetar los cotos y privilegios del monasterio ${ }^{40}$. Finalmente, en el año 1293 y ante las quejas del abad de Santa María de Oya contra el concejo de Valença do Miño y otros que pretendían usurparle la granja de Chamosinos que pertenecía al monasterio, ordenó a su merino Pedro Estévez que averiguara los términos de la granja, y si era justificada la queja del abad que obligase a devolver al monasterio lo que le habían quitado ${ }^{41}$. Conocemos además en el reinado de Dionis algunos documentos de intercambios como el realizado en 1308 con el obispo de Tuy ${ }^{42}$. La conexión de esta iglesia con el reino vecino es conocida no sólo por pertenecer a la diócesis de Braga, sino también por poseer beneficios eclesiásticos en tierras portuguesas, otra singularidad de esta especial relación de Galicia con Portugal originada tras la independencia del reino portugués ${ }^{43}$.

La especial protección de los monarcas portugueses al monasterio de Santa María de Oya continuó a lo largo de los años y resultan significativos del reinado

${ }^{36}$ 1284.01.18. Coimbra. A.H.N. Clero. Montederramo, carp. 1486, $\mathrm{n}^{\circ} 16$.

${ }^{37}$ 1281.12.24. Covilhã. A.H.N. Clero. Oya, carp. 1806, $\mathrm{n}^{\circ}$ 16. Cópia Notorial de 1293. SÁNCHEZ, op. cit., $\mathrm{n}^{\circ} 814$, p. 352.

${ }^{38}$ 1282.05.29. Punhete. A.H.N. Clero. Oya, carp. 1806, no 16. SÁNCHEZ, op. cit., n ${ }^{\circ}$ 818, p. 354.

${ }^{39}$ 1293.08.25. Lisboa. A.H.N. Clero. Oya, carp. 1810, $\mathrm{n}^{\circ} 3$. SÁNCHEZ, op. cit., $\mathrm{n}^{\circ}$ 892, p. 383.

${ }^{40}$ 1293.08.25. Lisboa. A.H.N. Clero. Oya, carp. 1810, n ${ }^{\circ}$. SÁNCHEZ, op. cit., $n^{\circ} 893$, p. 383.

${ }^{41}$ 1308.02.17. Santarem. A.H.N. Clero. Oya, carp. 1816, nº 15. SÁNCHEZ, op. cit., no 961, p. 409.

${ }^{42}$ 1308.01.01. Leiria. A.N.T.T. Gavetas, XIX, maço 3, doc. 41. SANTAREM, op. cit., T. I, seccão XV, p. 132.

${ }^{43} 1320$. Establecimiento de la tasa que el obispado de Tuy tenía que pagar al rey de Portugal por los beneficios eclesiásticos situados en el territorio Entre Douro e Minho. A.N.T.T. Sé de Coimbra, Livro branco, ff. 22v-25v; Mosteiro de Santa Cruz de Coimbra, livro 97, ff. 20v-24. COSTA, Padre Avelino Jesús da, «Comarca eclesiástica de Valença do Minho: antecedentes da diócesis de Viana do Castelo», en I Coloquio Galaico-Minhoto, Ponte de Lima, 1981, doc. 3, pp. 163-68. 
de Alfonso IV los documentos de 1326 en que el monarca tomó bajo su amparo al abad, al monasterio y a todas las heredades que este tenía en el reino de Portugal ${ }^{44}$, y de 1340 en que, a petición del abad de Oya, ordenó a su almojarife de Valença do Miño que le restituyese al monasterio las heredades que se le habían confiscado durante la guerra con Castilla ${ }^{45}$. La intervención de este monarca portugués no se circunscribió a este monasterio, sino que conocemos documentación de Alfonso IV referida a otros centros gallegos como al monasterio de Antealtares o a la iglesia de Santiago ${ }^{46}$, al monasterio de Santa María de Miranda ${ }^{47}$ y al de Montederramo ${ }^{48}$ y al obispado de Tuy ${ }^{49}$.

El monarca portugués Pedro I fruto de sus relaciones con Inés de Castro mantuvo una vinculación especial con Galicia, ya que no podemos olvidar la presencia y protagonismo de la familia Castro en los principales acontecimientos del

${ }^{44}$ 1326.02.22. Coimbra. A.H.N. Clero. Oya, leg. 1254. SÁNCHEZ, op. cit., nº 1022, p. 433.

${ }^{45}$ 1340.08.18. A.H.N. Clero. Oya, leg. 1256. SÁNCHEZ, op. cit., no 1092, p. 162. MARQUES, José, «O Mosteiro do Oia e a granja da Silva no contexto das relacões luso-castelhanas nos séculos XIV e XV», en Revista de História, Porto (1985), doc. 1, pp. 20-2; 1342.06.24. Oporto. Carta de Alfonso IV, dictada a petición del abad de Santa María de Oya, en la cual ordena a su almojarife de Valença do Miño, Pedro Carneiro, que entregue al citado monasterio los ganados, cubas y arcas que le había incautado con ocasión de la guerra con Castilla y con las cuales se había quedado después de recibir su anterior carta del 18 de agosto de 1340. AH.N. Clero. Oya, carp. 1828, $\mathrm{n}^{\circ} 5$; leg. 1256. SÁNCHEZ, op. cit., $\mathrm{n}^{\circ} 1100$, p. 456. MARQUES, art. cit., p. 22-3.

${ }^{46}$ 1334.09.06. Coimbra. Alfonso IV conocidas las pruebas presentadas por el monasterio de Antealtares le confirma en las jurisdicciones que poseía en Paradela e Mazarefes. A.N.T.T. Além Douro, liv. 2, ff. 194v-195. MARQUES, José, «D. Afonso IV e as jurisdições senhoriais GalaicoLeonesas no norte de Portugal», en Brigantia, XII, 4, (1981), doc. 1, pp. 185-86; 1336.09.06. Coimbra. Alfonso I otorga carta de sentencia al monasterio de Sampaio de Antealtares para que pueda colocar mayordomos en Paradela y Mazaretes y emplazar a sus habitantes. Chancelarias portuguesas: D. Afonso IV, Lisboa, 1992, vol. II (1336-1340), doc. 38, pp. 83-4; 1335.09.22. Coimbra. Alfonso IV respeta la jurisdicción que el cabildo de Santiago tenía en Correlha y exige que proceda a nombrar a un hombre bueno que reciba el juramento de juez electo para evitar trasladarse a Santiago. A.N.T.T. Chancelaria de D. Afonso IV, liv. 4, f. 80; Além Douro, liv. 2, ff. 233-234. MARQUES, «Afonso IV», doc. 1, pp. 186-88; 1341.07.24. Lisboa. Alfonso IV confirma al cabildo de Santiago la posesión del coto de Mouquim, Vila Nova de Famalição. A.N.T.T. Chancelaria de D. Afonso IV, liv. 4, ff. 73-73v; Além Douro, liv. 2, ff. 225v-226. MARQUES, art. cit., doc. 6, pp. 194-96.

${ }^{47}$ 1335.08.03. Guarda. Alfonso IV entrega al monasterio de Santa María de Miranda del obispado de Tuy la jurisdicción de su coto. Chancelarias portuguesas, Afonso IV, vol. II, doc. 48, pp. 101-05.

${ }^{48}$ 1335.11.16. Coimbra. Carta de Alfonso IV ordenando a los justicias de Braganza que se informen de los privilegios que el monasterio de Montederramo tenía sobre la granja de Cidones y otros lugares situados en el reino de Portugal y que no pasasen contra ellos. A.H.N. Clero. Montederramo, carp. 1493, n 13. SÁNCHEZ, op. cit., nº 1077, p. 456.

${ }^{49}$ 1338.09.09. Lisboa. Alfonso IV recibe dinero de las feligresías de Camiña y Viana que pertenecen al obispado de Tuy. Chancelarias portuguesas, Afonso IV, vol. II, doc. 131, pp. 229-30. 
momento ${ }^{50}$. La familia Castro pertenecía a la antigua nobleza formada en el siglo XII y tuvo una enorme importancia política y territorial en Galicia y León. Su influencia en la corte castellana era grande, así como notables sus relaciones con la familia real portuguesa. El linaje de los Castro comenzó sus contactos con el reino vecino a finales del siglo XIII. En 1298 Fernando Rodríguez de Castro solicitó a la regente de Castilla, María de Molina, la concesión de la tierra de Trastámara y al recibir una respuesta negativa, se desnaturalizó del reino y, apoyado por Dionis de Portugal, prosiguió la campaña en favor del Infante Juan, hermano del difunto Sancho de Castilla. Su hijo Pedro Fernández de Castro tuvo que refugiarse en Portugal al morir Fernando en el sitio de Monforte, y fue educado por el rey Dionis como si fuera de su familia. Dos hijos suyos, Fernando y Álvaro, jugaron un papel protagonista en las relaciones entre Portugal y Galicia ${ }^{51}$. Álvaro Pérez de Castro tuvo que huir del rey castellano y pasó a Portugal donde fue muy bien acogido por el Infante Pedro de Portugal, que estaba con su hermana Inés de Castro ${ }^{52}$. En el reino lusitano se le dieron heredades y según cuenta la crónica hizo allí su vida ${ }^{53}$. Pero la relación del rey Pedro I con mujeres gallegas no terminó con la muerte de Inés de Castro ya que sabemos que tuvo con doña Teresa, natural de Galicia, un hijo llamado Juan que sería después maestre de Avis y posteriormente rey de Portugal ${ }^{54}$.

Fueron frecuentes los conflictos entre la corona de Portugal y el obispo de Tuy debido a las tierras que este tenía en el vecino reino ${ }^{55}$ y por la pertenencia de esta iglesia a la diócesis portuguesa de Braga, con la consiguiente intervención real en

\footnotetext{
${ }^{50}$ Ver ROMERO PORTILLA, Paz, «Implicaciones gallegas en el caso de Inés de Castro», en Revista da Faculdade de Letras, História, II Série, Porto, vol. XV, (1998), pp. 1493-1508.

${ }^{51}$ Ver ROMERO PORTILLA, art. cit., pp. 1502-1508.

${ }^{52}$ Crónica de los reyes de Castilla, Don Pedro Primero, BAC, Madrid, 1953, T. I, Año 1353, cap. XXV-XXVI.

${ }^{53}$ 1381.11.02. El conde de Trastámara, Lemos y Sarriá, Pedro, dona a su alguacil mayor, Juan Alfonso, las tierras que pertenecieron a Álvaro Pérez de Castro, desnaturalizado en Portugal. A. Catedral de Ourense. Monástica. Pombeiro, $\mathrm{n}^{\circ}$ 4290. LUCAS ÁLVAREZ. El priorato benedictino, doc. 49, pp. 101-03; LEIRÓS FERNÁNDEZ, E., Catálogo de los pergaminos monacales del Archivo de la S. I. Catedral de Orense, Santiago, 1951, n 4290.

${ }^{54}$ LOPES, Fernão, Crónica do Senhor rei Dom Pedro, oitavo rei destes regnos, Porto, 1986, cap. I.

${ }^{55}$ 1357.10.18. Coimbra. Pedro I de Portugal para acabar con un conflicto entre la Corona y el obispo de Tuy debido al patronazgo de la iglesia de San Esteban de Valença do Miño renuncia a ese derecho en favor de la catedral de Tuy. A.N.T.T. Chancelaria de D. Pedro I, livro I, ff. 16v-17. Chancelarias portuguesas. D. Pedro I (1357-1367), Lisboa, 1984, doc. 181, pp. 70-1; COSTA, art. cit., doc. 4, pp. 169-70; BAQUERO MORENO, Humberto, Associação cultural galaica-minhota, $1^{\circ}$ Colóquio Galaico-Minhoto, Ponte de Lima, (1981), pp. 169-70.
} 
asuntos como la presentación de clérigos para algunos monasterios y parroquias ${ }^{56}$. Continuamos encontrando un especial trato hacia el monasterio de Santa María de Oya, como evidencia que, después de la disposición general del reino de Portugal en la que se había prohibido a las órdenes religiosas recibir bienes raíces, el rey Pedro I ordenó a su almojarifazgo de Valença do Miño que devolviera a dicho monasterio dos casas y una viña situadas en Camiña ${ }^{57}$, la restitución de los bienes que le habían sido incautados ${ }^{58}$, o cuando instó a su gobernador de Entre Douro e Minho a que no incluyera a este monasterio en el reparto de servicios reales, en atención a que Santa María de Oya pagaba anualmente al concejo de Valença do Miño por las heredades que tenía en este término ${ }^{59}$.

Los conflictos que enfrentaron a Castilla y Portugal durante el reinado de Fernando I motivaron unas intensas relaciones de las que hay reflejo en la documentación. En 1369 el rey portugués tuvo que abandonar Galicia al advertir que Enrique II de Castilla se dirigía hacia alli ${ }^{60}$. Mientras tenían lugar las negociaciones para la firma del tratado de Alcoutim ${ }^{61}$ entre los dos reinos, el rey castellano se encontraba en Tuy y el obispo de Ourense fue uno de sus embajadores enviados al reino portugués ${ }^{62}$.

${ }^{56}$ 1361.11.02. Évora. Pedro I consintió y otorgó la elección de Esteban Lorenço como prior y abad del monasterio de Ermelo que pertenecía al obispado de Tuy. Chancelarias portuguesas, $D$. Pedro I, doc. 604, p. 275; 1362.09.02. Óbidos. El rey de Portugal presentó al clérigo Vasco Martins para la iglesia de San Martinho de Soaio perteneciente al obispado de Tuy. Idem, doc. 685, p. 319; 1362.09.14. Óbidos. Pedro I presentó al clérigo Pero Anes para la iglesia de San Paio de Jola perteneciente al obispado de Tuy. Idem, doc. 687, p. 320; 1367.02.08. Porto de Mós. Pedro I presentó al clérigo Rui Tenrreiro para la iglesia de San Salvador de Bulhete del obispado de Tuy. Idem, doc. 1153 , p. 549. Sobre la importancia de Tuy en las relaciones con Portugal ver ROMERO PORTILLA, Paz, «Un observatorio privilegiado de las relaciones entre Castilla y Portugal: Tuy en la Edad Media», en Homenaje a José Marques, Porto (2003) En prensa.

${ }^{57}$ 1363.07.16. Camiña. A.H.N. Clero. Oya, carp. 1825, $n^{\circ} 5$; leg. 1260. SÁNCHEZ, op. cit., $\mathrm{n}^{\circ}$ 1161, pp. 487-88; MARQUES, art. cit., pp. 84-5.

${ }^{58} 1365.07 .04$. Ribeira de Coruche. Pedro I ordena a su almojarife y escribano de Valença do Miño que devuelvan al monasterio de Santa María de Oya los bienes raíces que éste poseía en su jurisdicción y que habían sido incautados para el rey. A.H.N. Clero. Oya, carp. 1835, nº 11 y 12; leg. 1260. SÁNCHEZ, op. cit., n 1162, p. 488; MARQUES, art. cit., pp. 25-7

${ }^{59}$ 1365.10.16. Leiria. A.H.N. Clero. Oya, leg. 1260. SÁNCHEZ, op. cit., nº 1165, p. 489.

${ }^{60}$ 1369. (07-08) LOPES, Fernão, Crónica do Senhor rei Dom Fernando, nono rei destes regnos, Porto, 1979, cap. XXXII; LEÃO, Duarte Nunes de, Crónicas dos reis de Portugal, Chronica del rei Dom Fernando, Porto, 1975, pp. 334-36. SANTAREM, op. cit., T. I, pp. 215-16.

${ }^{61} 1371.03 .31$.

${ }^{62}$ 1372.04. Fernando I de Portugal envió una embajada a Enrique II de Castilla, que se encontraba en Tuy, para la reforma del tratado de Alcoutim. LOPES, op. cit., cap. LIII; LEÃO, op. cit., pp. 345-46; SANTAREM, op. cit., T. I, pp. 227-28; 1372.05. Enrique II mandó una embajada a Portugal formada entre otros por el obispo de Ourense Juan, para recibir el juramento de Fernando I igual 
La firma del tratado significó que Fernando I olvidaba sus aspiraciones al trono castellano y el derrumbamiento de la resistencia legitimista. Las ciudades gallegas afiliadas a Portugal durante los enfrentamientos aceptaron sin nuevos levantamientos la soberanía castellana. Únicamente Tuy continuó durante algún tiempo como baluarte de la rebeldía. Otro momento significativo tuvo su origen en el matrimonio del rey castellano Juan I con la hija de Fernando I de Portugal. La crisis generada en el reino vecino tras la entrada del monarca de Castilla y la batalla de Aljubarrota ocasionaron profundos cambios políticos, sociales y económicos en el reino portugués. Algunos documentos que recogen el compromiso matrimonial hacen también referencia a Galicia ${ }^{63}$.

En los años 1386-1390 Galicia sufrió la invasión inglesa ${ }^{64}$. El duque de Lancaster y su mujer Constanza, hija de Pedro I de Castilla, autoproclamados reyes de Castilla, habían desembarcado en A Coruña ${ }^{65} \mathrm{y}$, apoyados por el monarca portugués, trataban de hacerse con el trono. Como consecuencia de esta ayuda portuguesa a las pretensiones del duque de Lancaster al trono castellano se firmará el tratado de alianza y casamiento celebrado en 1386 entre Juan I de Portugal y una hija del duque ${ }^{66}$.

que el monarca castellano había hecho en Tuy para el tratado de Alcoutim. SANTAREM, op. cit., T. I, pp. 228-29.

${ }^{63}$ 1383.03.12. Tordesillas. El arzobispo de Santiago, Juan García Manrique, recibe poderes para confirmar el casamiento del rey Juan con Beatriz de Portugal. Archivo General de Simancas. Patronato Real, leg. 47, f. 46. ARNAUT, Salvador Dias, A crise nacional de fins do século XIV, Coimbra, 1960, doc. 26, pp. 369-76. SUÁREZ FERNÁNDEZ, Luis, Historia del reinado de Juan I de Castilla, Madrid, 1982, T. II, doc. 334, p. 500; 1383. Instrucciones dadas a Pedro de Luna y al arzobispo de Santiago sobre algunas referencias a las cartas enviadas por el rey Fernando de Portugal. A. G. S. P. R., leg. 47, f. 44. ARNAUT, op. cit., pp. 394-97; SUÁREZ, op. cit., doc. 344, pp. 512-16; 1383.05.11. Badajoz. Juan García Manrique, arzobispo de Santiago, recibe poderes completos para confirmar y prorrogar los plazos de los desposorios. A. G. S. P. R., leg. 47, f. 46. ARNAUT, op. cit., pp. 391-93; SUÁREZ, op. cit., doc. 346, p. 517.

${ }^{64}$ LOPES, Fernão, Crónica de D. João I, Barcelos, 1990, vol. II, cap. LXXXII. Crónicas de los Reyes de Castilla, Don Enrique II, BAC, vol. II, año 1386, cap. VI y siguientes.

${ }^{65}$ 1386.07. El duque de Lancaster como rey de Castilla envía cartas a Juan I de Portugal informándole de su llegada a Coruña llevando consigo a su mujer e hijos, para reclamar para sí el reino de Castilla que por derecho le pertenecía. LOPES, op. cit., vol. II, cap. LXXXII; SANTAREM, op. cit., T. I, pp. 266-67; 1386. Juan I de Portugal mandó con Vasco Martins y Lourenço Anes Fogaça sus saludos al duque de Lancaster como rey de Castilla a su llegada a Galicia. LOPES, op. cit., vol. II, cap. LXXXIX-XC; SANTAREM, op. cit., T. I, p. 267; LEÃO, Crónica del rey D. João I, cap. LXVII, pp. 609-13.

${ }^{66}$ 1386.11.11. Celanova. LOPES, op, cit., vol. II, cap. XCII; LEÃO, op. cit., cap. LXVIII, pp. 613-15; SANTAREM, op. cit., T. I, p. 270; 1386.11. Juan I de Portugal envía una embajada a los duques de Lancaster que se encontraban en Celanova para que la duquesa ratificase el tratado de alianza y casamiento acordado con su marido. Ibídem.

Cuadernos de Estudios Gallegos, Tomo LI, Fascículo 117, Santiago 2004. (Págs. 219 - 237) 
En este tiempo tuvo lugar una entrada portuguesa por Tuy. El rey lusitano cercó primero Melgaço, villa cercana a la frontera, a media legua del Miño y a cinco de Tuy, que estaba en manos amigas del rey castellano ${ }^{67}$. Posteriormente cercó y tomó la ciudad de Tuy ${ }^{68}$. Durante algún tiempo dicha ciudad y Salvatierra estuvieron bajo dominio portugués gracias al apoyo de algunos miembros de la nobleza local, si bien el monarca castellano recuperó pronto la posesión de ambas ciudades.

Durante el reinado de Juan I el monasterio de Santa María de Oya continuó recibiendo la tradicional protección de los monarcas portugueses, y así encontramos documentos como el del año 1389 en que el monarca lusitano ordenó a todos los funcionarios de su reino que devolvieran a dicho monasterio todas las propiedades que tenía en Portugal y le habían sido incautadas ${ }^{69}$, o la provisión de 1393 a Juan d'Alpoy, oidor entre el Duero y el Miño, comunicándole que ha recibido una queja del abad del monasterio según la cual los recaudadores no respetan los privilegios del monasterio concedidos por Alfonso III y Dionis ${ }^{70}$. Cabe destacar por su interés en las relaciones con Galicia la provisión de Juan I del año 1397 en que comunicó a todos los funcionarios del reino que protegía al monasterio de Santa María de Oya y ordenó, a pesar de la guerra mantenida con Castilla, que no le fueran embargados sus propiedades, vasallos y ganado que el monasterio poseía en Portugal. Ese mismo año concedió al abad de Santa María de Oya una carta de protección y seguro para residir en territorio portugués con garantía de libre tránsito por la frontera para visitar el monasterio ${ }^{71}$, documento renovado el año $1400^{72}$. De 1402 es otra provisión del monarca portugués dirigida a su frontero mayor en la ciudad de Tuy, Gonzalo Vázquez, y a todos los fronteros de la ribera del Miño comunicándoles que ha tomado bajo su protección este monasterio y sus bienes, $\mathrm{y}$ que ha recibido quejas del abad del monasterio contra Gonzalo Vázquez, instándoles a cumplir fielmente lo contenido en sus cartas a favor de dicho monasterio ${ }^{73}$.

${ }^{67}$ LOPES, op. cit., vol. II, cap. CXXXIII.

${ }^{68}$ Idem, vol. II, cap. CXXXIX. Más tarde la ciudad fue nuevamente cercada. Ver cap. CLXVIII.

${ }^{69}$ 1389.12.21. Guimarães. A.H.N. Clero. Oya, carp. 1837, nº 15. SÁNCHEZ, op. cit., nº 1263, p. 528 .

${ }^{70}$ 1393.02.14. Lisboa. A.H.N. Clero. Oya, carp. 1838, $\mathrm{n}^{\circ} 1$. SÁNCHEZ, op. cit., $\mathrm{n}^{\circ} 1272$, pp. 531-32. MARQUES, José, Relações entre Portugal e Castela nos finais da Idade Média: Cartas inéditas de D. João I do Arquivo Nacional de Madrid, Braga, 1985, nº 2, pp. 273-75.

${ }^{71} 1397.08 .28$. Santarem. A.H.N. Clero. Oya, carp.1838, n 16. SÁNCHEZ, op. cit., no 1288, p. 538. MARQUES, op. cit., $\mathrm{n}^{\circ}$ 3, pp. 275-76.

72 1400.07.30. A.H.N. Clero. Oya, carp. 1838, n² 20. SÁNCHEZ, op. cit., nº 1291, p. 539; MARQUES, op. cit., $\mathrm{n}^{\circ} 4$, pp. 276-77.

${ }^{73}$ 1402.02.11. Montemor-Novo. A.H.N. Clero. Oya, carp. 1839, $\mathrm{n}^{\circ}$ 5. SÁNCHEZ, op. cit., $\mathrm{n}^{\circ}$ 1301, p. 543; MARQUES, op. cit., nº 6, p. 279. 
Para terminar con los documentos de Juan I recogemos un albalá, con firma del Infante Duarte, en que ordenaba a Fernão Lopes, encargado del archivo de la cancillería real, que copiase los documentos referentes a las propiedades que el monasterio tenía en Fandega da $\mathrm{Fe}^{74}$.

Siguiendo con documentos reales referentes a Santa María de Oya contamos con el documento de Duarte de Portugal de 1434 en que otorgaba privilegio al monasterio $^{75}$, y los de Alfonso V. De este último con uno de 1449 en que concede carta de seguridad al abad del monasterio y a todos sus bienes ${ }^{76}$, otro de 1451 en el que otorga un nuevo privilegio de protección a dicho monasterio ${ }^{77} \mathrm{y}$, finalmente, una provisión del año 1455, dictada a petición del abad de Oya, dirigida a los jueces de Valença do Miño, Camiña y Villanova donde les ordena dar posesión de la granja de Silva a dicho abad y que no consientan que nadie le moleste en su dominio $^{78}$.

En 1437 Duarte de Portugal maniobró ante la corte pontificia y en el concilio de Basilea tratando de evitar que Castilla recuperase los bienes de las diócesis de Tuy y Badajoz en territorio lusitano, para lo cual amenazó con abandonar la guerra contra los infieles y cancelar una armada para África con objeto de difundir la $\mathrm{fe}^{79}$. El año 1439 Alfonso V confirma a Vasco Ferrandes el cargo de merino del obispado de Tuy, lo que muestra que los reyes portugueses continuaban interviniendo en las cuestiones referentes a esta iglesia ${ }^{80}$. Por fin, en 1444 Portugal logró del Papa

${ }^{74}$ 1423.10.12. Lisboa. A.H.N. Clero. Oya, carp. 1843, nº 1. SÁNCHEZ, op. cit., nº 1342, p. 559. La referencia de este albalá se tiene por la carta de 1423.11.02. Lisboa, en la que Fernão Lopes extiende en nombre del monarca una copia certificada de las posesiones del monasterio de Santa María de Oya referente a Fandega da Fe. A.H.N. Leg. 1265. SÁNCHEZ, op. cit., nº 1343, p. 560.

${ }^{75}$ 1434.11.06. Lisboa. A.N.T.T. Livro de Extras, f. 158v. SANTAREM, op. cit., T. I, p. 48.

${ }^{76}$ 1449.11.12. A.N.T.T. Livro de Extras, f. 76. SANTAREM, op. cit., T. I, p. 49.

${ }^{77}$ 1451.12.15. A.N.T.T. Livro de Extras, f. 116v. SANTAREM, op. cit., T. I, p. 50.

${ }^{78}$ 1455.10.07. A.H.N. Clero. Oya, carp. 1847, $\mathrm{n}^{\circ} 3$. Traslado notarial. SÁNCHEZ, op. cit., $\mathrm{n}^{\circ}$ 1358, pp. 565-66.

${ }^{79}$ Varios son los documentos que reflejan los manejos del rey Duarte. 1437.03.23. Santarem. B. M. L. F. Fondo Ashburnam, cod. 1792, vol. 1, p. 5. Monumenta Henricina, Comissão Executiva das Comemorações do V Centenario da morte do Infante D. Henrique, 1960 y ss, vol. VI, doc. 16, pp. 32-5. 1437.05.16. Lisboa. B. M. L. F. Fondo Ashburnam, cod. 1792, vol. 1, pp. 17-21. Monumenta, doc. 23, pp. 44-9. 1437.06.25. Lisboa. Monumenta, cod. 1792, vol. 2, pp. 29-30. Idem, doc. 36, pp. 68-9. 1437.06.27. Lisboa. Monumenta, cod. 1792, vol. 2, pp. 13-4. Monumenta, doc. 37, pp. 70-2. 1437.06.27. Lisboa. Monumenta, cod. 1792, vol. 2, p. 265. I Monumenta, doc. 38, pp. 73-5.

${ }^{80}$ 1439. Lisboa. A.N.T.T. Chancelaria de Alfonso V, libro 18, f. 78. Chartularii Universitatis Portugalensis (1288-1537), Lisboa, 1970, vol. IV (1431-1445), doc. 1192, p. 272. Después de la bula Romanus Pontifex en la que se otorgaban los bienes de la iglesia de Tuy en territorio portugués a la diócesis de Ceuta, encontramos al rey Alfonso V confirmando los privilegios de los frailes del 
Eugenio IV el documento que atribuía al obispado de Ceuta las rentas que integraban los obispados de Tuy y Badajoz en Portugal ${ }^{81}$. La anexión fue ratificada por Nicolás V en $1452^{82}$ y por Calixto III en $1456^{83}$. Finalmente del año 1477 es el documento en que el administrador del obispado de Tuy en territorio portugués, después de considerar las razones esgrimidas por la Colegiata de San Esteban de Valença do Minho, la anexiona a perpetuidad ${ }^{84}$.

Podemos confirmar a modo de conclusión que la documentación estudiada, procedente principalmente de la cancillería real portuguesa, refleja una estrecha vinculación de este reino con Galicia. Aspectos históricos, geográficos, sociales, económicos y eclesiásticos originaron una especial relación entre estos dos territorios a lo largo de la Edad Media. Una historia vivida de manera interdependiente durante muchos de los principales acontecimientos de estos siglos hace imprescindible beber de las fuentes archivísticas portuguesas para tener un mayor y más completo conocimiento de la historia de la Galicia medieval. Continúa pues viva esa vinculación entre la franja atántica de la Península Ibérica en los albores del tercer milenio.

monasterio de Santo Domingo en Tuy. 1450.01.10. Évora. A.N.T.T. Livro de Extras, f. 88. SANTARÉM, op, cit., T. I, secção III, p. 49. 1462.07.02. Valença. A.N.T.T. Chancelaria de Alfonso $V$, livro 1 , f. 40, doc. 3. MARQUES, José, Relaçôes económicas do norte de Portugal com o reino de Castela, no século XV, Braga, 1978, doc. 7. A finales del siglo XV Manuel de Portugal confirmó todos los privilegios que habían sido dados al convento de Santo Domingo de Tuy. 1497.07.19. Évora. A.H.N. Clero. Santo Domingo de Tuy, carp. 1874, $\mathrm{n}^{\circ} 18$. MANSO PORTO, Carmen, El arte de la Orden de Santo Domingo en la Galicia Medieval, Madrid, 1991, doc. 17, p. 51.

${ }^{81}$ 1444.07.14. Roma. Bula Romanus Pontifex por la cual Eugenio IV separa completamente de las diócesis de Tuy y Badajoz ciertos bienes que ambas poseían en el reino de Portugal y los incorpora a la de Ceuta. A.N.T.T. Bulas, maço 4, n 3 . MARQUES, João Martins da Silva, Descobrimentos Portugueses: documentos para a sua História, Lisboa, 1988, vol. I, doc. 115, pp. 144-46.

82 1452.06.27. Roma. Bula Etsi de Singulis Orbis de Nicolás V al obispo de Évora por la cual incorpora en la diócesis de Ceuta ciertas tierras que pertenecían a las diócesis de Badajoz y Tuy y estaban en territorio portugués. A.N.T.T. Bulas, maço 8, $\mathrm{n}^{\circ} 11$. MARQUES, Descobrimentos Portugueses, vol. I, doc. 394, pp. 494-98; 1452.08.05. Roma. Bula Ex Clementi Prouisione de Nicolás V que, recordando la bula Etsi de Singulis Orbis, aprueba y confirma la bula Romanus Pontifex. Monumenta Henricina, vol. XI, doc. 153, pp. 213-18.

${ }^{83}$ 1456.02.29. Roma. Bula Apostolica Sedis Provedentis de Calixto III por la cual confirma las bulas de Eugenio IV y Nicolás V en las que separaban de los obispados de Tuy y Badajoz los bienes que poseían en el reino de Portugal y los incorporaban a la diócesis de Ceuta. A.N.T.T. Bulas, maço 5, $\mathrm{n}^{\mathrm{o}}$ 7; A. S. V., vol. 440, f. 282v. MARQUES, Descobrimentos Portugueses, vol. I, doc. 136, pp. 249-53. Monumenta Henricina, vol. XII, doc. 129, pp. 258-63.

${ }^{84}$ 1477.06.23. Oporto. A.N.T.T. Colegiata de Santo Estevão de Valença do Minho, $n^{\circ} 743$. COSTA, Comarca eclesiástica, doc. 7, pp. 173-76. 